Int. J. Electrochem. Sci., 15 (2020) 9066 - 9080

International Journal of

ELECTROCHEMICAL

SCIENCE

WWW.electrochemsci.org

\title{
Experimental, DFT and QSAR models for the discovery of new pyrazines corrosion inhibitors for steel in oilfield acidizing environment
}

\author{
I. B. Obot ${ }^{*}$ and S. A. Umoren \\ Center of Research Excellence in Corrosion, Research Institute, King Fahd University of Petroleum \\ and Minerals, Dhahran 31261, Saudi Arabia \\ *E-mail: obot@kfupm.edu.sa
}

doi: $10.20964 / 2020.09 .72$

Received: 18 December 2019 / Accepted: 18 March 2020 / Published: 10 August 2020

Eight (8) pyrazine derivatives were tested as mild steel corrosion inhibitors in a simulated oil field acidizing environment. Immersion tests and DFT calculations were adopted for the study. Immersion tests were carried out at $0.2 \mathrm{wt}$. \% inhibitor concentration at $25^{\circ} \mathrm{C}$ for a total duration of $24 \mathrm{~h}$. The results showed that all the pyrazine derivatives tested protected the steel to various extents in the acid medium. Pyrazine carboxamide (Pyrazine E) exhibited the highest inhibition efficiency among the pyrazine derivatives investigated. The resulting molecular descriptors obtained from DFT calculations were correlated with the experimental inhibition efficiency to develop QSAR model. Multiple linear regression was utilized to correlate the inhibition efficiency with the molecular descriptors at a $95 \%$ confidence interval. This work revealed that the inhibition efficiencies of the studied pyrazine molecules were influenced by their $E_{L U M O}$, dipole moment (DM) and the molecular volume (MV). Based on the QSAR model developed, four new pyrazine derivatives were designed, and their inhibition efficiencies predicted.

Keywords: DFT; QSAR; pyrazine derivatives; corrosion inhibition efficiency; Step wise regression.

\section{$\underline{\text { FULL TEXT }}$}

(C) 2020 The Authors. Published by ESG (www.electrochemsci.org). This article is an open access article distributed under the terms and conditions of the Creative Commons Attribution license (http://creativecommons.org/licenses/by/4.0/). 